\title{
Complex robotic correction for complex degenerative mitral valve disease
}

\author{
Danny Ramzy, Joshua Chung, Wen Cheng, Michele A. De Robertis, James Mirocha, Alfredo Trento \\ Division of Cardiothoracic Surgery, Cedars-Sinai Medical Center, Los Angeles, California, USA \\ Correspondence to: Danny Ramzy, MD, PhD, FRCSC, FACC, FACS. Division of Cardiothoracic Surgery, Cedars-Sinai Medical Center, 127 S San \\ Vicente Blvd, A3015, Los Angeles, California 90048, USA. Email: danny.ramzy@cshs.org.
}

Submitted Jan 10, 2017. Accepted for publication Jan 11, 2017.

doi: 10.21037/acs.2017.01.08

View this article at: http://dx.doi.org/10.21037/acs.2017.01.08

\section{Clinical vignette}

The gold standard treatment of degenerative mitral valve disease remains surgical repair. The classic repair described by Dr. Carpentier (1) with leaflet resection and annuloplasty remains the primary technique for mitral repair. Other techniques such as the "American correction" (2) or artificial chordae have been introduced with similar success rates. Innovations in surgical approach over the past 20 years have led to the development of minimally invasive access to the mitral valve. Fifteen years ago, Dr. Chitwood pioneered the use of the da Vinci Robotic Surgical System (Intuitive Surgical, Inc., Sunny Vale, California, USA) for mitral valve repair $(3,4)$. His excellent outcomes and those of others led to an increased utilization of the robotic approach to the mitral valve (1-10). Robotic correction of mitral regurgitation was initially limited to less complex mitral valve pathologies. However, with improvement in technologies and experience, complex repair of degenerative mitral regurgitation is possible.

A 44-year-old gentleman was referred with asymptomatic severe mitral regurgitation. His past medical history was unremarkable except for osteoarthritis of the hip. Physical examination was normal except for a grade $\mathrm{V}$ holosystolic murmur in the left fifth intercostal space (ICS) radiating to the axilla. Transthoracic echocardiography (TTE) demonstrated severe mitral regurgitation, severe bileaflet prolapse, predominantly involving the posterior leaflet with flail of the anterior leaflet and evidence of ruptured chordae. Left and right ventricular function were normal. The rest of the cardiac work-up was normal, demonstrating no coronary artery disease and absence of peripheral vascular disease.

\section{Surgical techniques}

Pre-operative assessment

The patient was positioned in slight left lateral decubitus position after induction of general anesthesia and placement of the double lumen endotracheal tube, routine monitoring lines and a TEE probe. All patients undergo three-dimensional reconstructed transesophageal echocardiography (TEE) imaging, and this patient's images demonstrated a severe 4+ mitral regurgitation jet resulting from bileaflet prolapse and anterior leaflet flail, as well as excessive leaflet motion of all leaflet segments.

\section{Operative technique}

Our current standard practice has been previously described (5) (Video 1). After the patient is positioned supine with the right side of the chest elevated, the right lung is deflated, and a 3- to $4-\mathrm{cm}$ right inframammary incision through the fourth or fifth ICS is used as the working port. Trocars for the robotic instrument arms, 14-gauge angiocatheters for traction sutures, and a 20-F DLP (Medtronic, Inc., Minneapolis, Minn, USA) intracardiac sump drain are inserted through a separate stab-wound incision.

The patient is heparinized and the femoral vessels are cannulated for cardiopulmonary bypass. A two-stage venous cannula is placed through the femoral vein under TEE guidance to ensure proper placement for venous drainage with vacuum assistance. The pericardium is incised ventral to the phrenic nerve. A transthoracic aortic clamp (Scanlan International, Minneapolis, Minn, USA) is positioned through the third ICS in the midaxillary line. An ascending aortic root vent (DLP 14-gauage 7 F; Medtronic, Inc.) is 
placed under direct vision. The da Vinci robot is positioned to the patient's left side, and the instrument arms are placed endoscopically. Bypass is established, and the patient is cooled to $32{ }^{\circ} \mathrm{C}$. Once cold, the cross-clamp is positioned and clamped under endoscopic vision followed by $1.2 \mathrm{~L}$ of Del Nido cardiopleagia. No redosing necessary was during the case. Once asystole is achieved, a standard left interatrial incision is made using the robot, and the left atrial roof retractor is positioned for mitral valve exposure.

The repair consisted of a large triangular resection of $\mathrm{P} 2$. The resultant cleft was then closed with several figureof-eight sutures of 4-0 Cardionyl. Two sets of chordae were then inserted at the level of $\mathrm{A} 2$, one from the anterolateral papillary muscle, one from the posteromedial papillary muscle. There was a flail chord at A2, which was resected. There was prolapse of $\mathrm{P} 3-\mathrm{A} 3$, and this was repaired using an advancement of the medial commissure with figure-ofeight sutures of 4-0 Cardionyl, effectively resulting in a commissural closure. Two of these sutures were employed. The valve was then tested and found to be competent. The repair was then completed using a \#39 ATS band (Medtronic, Inc., Minneapolis, MN, USA) which was implanted using interrupted 2-0 Ethibond (Ethicon Inc., Somerville, NJ, USA) sutures. After all the sutures were inserted into the band and tied and cut, the left atriotomy incision was closed using a running suture technique of 4-0 Gore-Tex. Before completing the closure, the left ventricle and aorta were allowed to fill up with blood in order to evacuate as much air as possible from the heart. The crossclamp was then removed and the patient was rewarmed. The patient was weaned off bypass without requiring any inotropic support. Intraoperative TEE confirmed the presence of a good repair with no residual MR. Venous and arterial cannulae were removed, the right femoral artery and vein were repaired, and the right groin incision was closed. Two temporary ventricular pacemaker wires were inserted in the usual fashion as well as three chest tubes, one in the pericardium and two in the right side of the chest. The minithoracotomy incision was then closed anatomically using pericostal sutures in layers. The patient tolerated the procedure well and left the operating room in a satisfactory condition. The post-operative course was uncomplicated and the patient was transferred to the floor the following morning and discharged on post-operative day 4 . His one month follow-up TTE showed trivial MR.

\section{Comments}

Since October 2000, the use of robotic mitral repair has steadily grown. Our institutional experience dates back to 2005. All patients with MR considered to be reparable, including all degenerative and endocarditic etiologies, were approached using the da Vinci system. With increasing experience and improved outcomes compared to the standard sternotomy approach, we found an increase in referral of more complex mitral pathology leading to a greater proportion of patients with bileaflet pathology and Barlow's disease. Robotic mitral valve repair is safe and associated with low mortality of less than $1 \%$ in our hands. Our experience shows that all complex valve repairs previously approached through a sternotomy can be performed robotically. We would argue that the robotic approach leads to greater and better repair rates than the standard approach. We exclusively follow an echo-guided approach to valve repair and not all abnormalities seen on valve inspection are repaired, such as clefts that are not causing regurgitation. The reason for this approach is that valve sutures inevitably cause some leaflet scarring which can reduce long-term durability, especially in complex valve repairs. In summary, complex mitral valve repair can be performed robotically and should not be a deterring factor when considering whether a patient can undergo robotic repair of their mitral valve.

\section{Acknowledgements}

None.

\section{Footnote}

Conflicts of Interest: The authors have no conflicts of interest to declare.

\section{References}

1. Carpentier A. Cardiac valve surgery--the "French correction". J Thorac Cardiovasc Surg 1983;86:323-37.

2. Lawrie GM. Mitral valve: toward complete repairability. Surg Technol Int 2006;15:189-97.

3. Felger JE, Nifong LW, Chitwood WR Jr. The evolution and early experience with robot-assisted mitral valve surgery. Curr Surg 2001;58:570-5.

4. Felger JE, Chitwood WR Jr, Nifong LW, et al. Evolution of mitral valve surgery: toward a totally endoscopic approach. Ann Thorac Surg 2001;72:1203-8; discussion 1208-9.

5. Cheng W, Fontana GP, De Robertis MA, et al. Is robotic 
mitral valve repair a reproducible approach? J Thorac Cardiovasc Surg 2010;139:628-33.

6. Nifong LW, Rodriguez E, Chitwood WR Jr. 540 consecutive robotic mitral valve repairs including concomitant atrial fibrillation cryoablation. Ann Thorac Surg 2012;94:38-42; discussion 43.

7. Suri RM, Antiel RM, Burkhart HM, et al. Quality of life after early mitral valve repair using conventional and robotic approaches. Ann Thorac Surg 2012;93:761-9.

8. Suri RM, Burkhart HM, Daly RC, et al. Robotic mitral valve repair for all prolapse subsets using techniques

Cite this article as: Ramzy D, Chung J, Cheng W, De Robertis MA, Mirocha J, Trento A. Complex robotic correction for complex degenerative mitral valve disease. Ann Cardiothorac Surg 2017;6(1):70-72. doi: 10.21037/acs.2017.01.08 identical to open valvuloplasty: establishing the benchmark against which percutaneous interventions should be judged. J Thorac Cardiovasc Surg 2011;142:970-9.

9. Suri RM, Burkhart HM, Rehfeldt KH, et al. Robotic mitral valve repair for all categories of leaflet prolapse: improving patient appeal and advancing standard of care. Mayo Clin Proc 2011;86:838-44.

10. Svensson LG, Atik FA, Cosgrove DM, et al. Minimally invasive versus conventional mitral valve surgery: a propensity-matched comparison. J Thorac Cardiovasc Surg 2010;139:926-32.e1-2. 